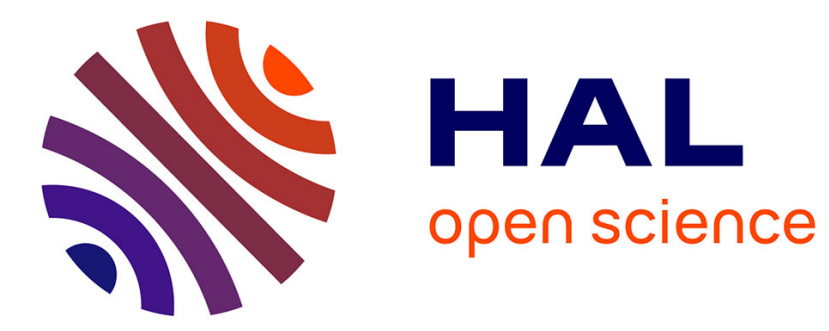

\title{
Atom probe tomography investigation of assisted precipitation of secondary hardening carbides in a medium carbon martensitic steels
}

\author{
F. Danoix, R. Danoix, J. Akre, A. Grellier, Denis Delagnes
}

\section{To cite this version:}

F. Danoix, R. Danoix, J. Akre, A. Grellier, Denis Delagnes. Atom probe tomography investigation of assisted precipitation of secondary hardening carbides in a medium carbon martensitic steels. Journal of Microscopy, 2011, 244 (3), pp.305-310. 10.1111/j.1365-2818.2011.03537.x . hal-01715078

\author{
HAL Id: hal-01715078 \\ https://hal.science/hal-01715078
}

Submitted on 6 Nov 2018

HAL is a multi-disciplinary open access archive for the deposit and dissemination of scientific research documents, whether they are published or not. The documents may come from teaching and research institutions in France or abroad, or from public or private research centers.
L'archive ouverte pluridisciplinaire HAL, est destinée au dépôt et à la diffusion de documents scientifiques de niveau recherche, publiés ou non, émanant des établissements d'enseignement et de recherche français ou étrangers, des laboratoires publics ou privés. 


\title{
Atom probe tomography investigation of assisted precipitation of secondary hardening carbides in a medium carbon martensitic steels
}

\author{
F. DANOIX*, R. DANOIX*, J. AKRE*, A. GRELLIER $\dagger$ \\ \& D. DELAGNES $\ddagger$ \\ *Université de Rouen, Groupe de Physique des Matériaux, Institut des Matériaux de Rouen, France \\ $\dagger$ Aubert \& Duval, Groupe Recherche et Développement, Aciérie des Ancizes, Les Ancizes, France \\ $\ddagger$ Université de Toulouse, INSA, UPS, Mines Albi, ISAE; Institut Clément Ader; Ecole des Mines \\ d'Albi, Campus Jarlard, Albi, France
}

Key words. Carbides, field ion microscopy (FIM), heterogeneous nucleation of phase transformations, martensitic steels, three-dimensional atom probe (3DAP).

\begin{abstract}
Summary
A medium carbon martensitic steel containing nanometer scale secondary hardening carbides and intermetallic particles is investigated by field ion microscopy and atom probe tomography. The interaction between the concomitant precipitations of both types of particles is investigated. It is shown that the presence of the intermetallic phase affects the nucleation mechanism and the spatial distribution of the secondary hardening carbides, which shifts from heterogeneous on dislocations to heterogeneous on the intermetallic particles.
\end{abstract}

\section{Introduction}

Martensitic carbon steels are known for their excellent mechanical properties, in particular ultimate tensile strength can reach more than $2000 \mathrm{MPa}$ at room temperature. These mechanical properties initially originate from the tetragonal martensitic matrix, further improved by tempering, generally in the temperature range $500-700^{\circ} \mathrm{C}$. This treatment, known as 'stage IV' in the tempering sequence of martensite, is characterised by the precipitation of nanometric carbides. These alloyed carbides contain $\mathrm{Cr}$, Mo V and/or W, depending on the initial composition of the steel grade. They are referred as secondary hardening carbides. Iron carbides

Correspondence to: F. Danoix, Université de Rouen, Groupe de Physique des Matériaux, UMR CNRS 6634, Faculté des Sciences de Rouen, Avenue de l'Université, 76801 Saint Etienne du Rouvray, Cedex, France. Tel: +33 232 955053; Fax: +33232 955032; e-mail: frederic.danoix@univ-rouen.fr (mainly $\mathrm{Fe}_{2.4} \mathrm{C}$ epsilon carbide and $\mathrm{Fe}_{3} \mathrm{C}$ cementite) are supposed to precipitate, preventing the quick recovery of the microstructure, but resulting in a relatively limited ultimate tensile strength. Maraging steel is another major class of martensitic steels. They are carbon free, and contain a large amount of nickel (generally $18 \mathrm{wt} \%$ ). Maraging steels usually exhibit a lower ultimate tensile strength, but larger fracture toughness (K1c) than conventional martensitic steel containing carbon. These improved fracture toughness properties are usually associated with a dense and finely dispersed distribution of nanometric intermetallic precipitates, for instance $\mathrm{Ni}_{3} \mathrm{Mo}, \mathrm{Ni}_{3} \mathrm{Ti}$..., depending on the composition of the steel.

New ranges of martensitic steels, combining carbide and intermetallic precipitations have been developed (Garrison \& Strychor, 1988; Hamano, 1993). These new steels exhibit a marked improvement of the ultimate tensile strength/K1c compromise. The reasons for this improvement, and in particular the respective roles of each type of precipitation, are still unknown. The work presented in this paper is part of a larger study aiming to better understand the mechanical response of such materials. This work focuses on understanding the synergy between the two precipitation mechanisms, and shows the role of the intermetallic precipitation on the carbide formation. The use of field ion microscopy (FIM) and atom probe tomography techniques gives access to the main characteristics of both the types of precipitates in three dimensions at the nanometer scale. Spatial distribution and number densities of precipitates, as well as their possible interactions, are studied in detail with these techniques. 
Table 1. Composition of the two investigated steels (wt\%).

\begin{tabular}{llllllll}
\hline Heat & C & Cr & Co & Ni & Mo & Al & Fe \\
\hline Steel 1014 & 0.2 & 2.5 & 10 & 14 & 1.4 & 0.9 & bal \\
Al free & 0.2 & 2.5 & 10 & 14 & 1.4 & - & bal \\
\hline
\end{tabular}

\section{Experimental}

Two different grades of the investigated material were analysed, with compositions given in Table 1 . The first one is a commercially produced alloy, hereafter referred as steel 1014 (standing for Co and $\mathrm{Ni}$ contents, respectively), which will serve as the reference material. The second one is an experimental grade, derived from steel 1014, where the aluminium content was reduced to 0 , and thus will be referred as $\mathrm{Al}$ free steel. $\mathrm{Al}$ has been removed in order to prevent the precipitation of $\mathrm{NiAl}$ intermetallic particles, and thus illustrate the influence of this second phase on the precipitation mechanism of the secondary hardening carbides. All specimens were austenitized at $900^{\circ} \mathrm{C}$ for $1 \mathrm{~h}$, quenched down to $-80^{\circ} \mathrm{C}$ and held for $8 \mathrm{~h}$ at this temperature in order to ensure a fully martensitic transformation. The amount of retained austenite after this cryogenic treatment is so low that it cannot be estimated X-ray analysis. The alloy was held at $200^{\circ} \mathrm{C}$ for $8 \mathrm{~h}$, cooled down to room temperature and then tempered at $500^{\circ} \mathrm{C}$ for $1 \mathrm{~h}$.

Conventional FIM and three-dimensional field ion microscopy (3DFIM) investigations were carried out at $80 \mathrm{~K}$, using, respectively, neon and a mixture of neon and hydrogen as imaging gases. Conventional FIM micrographs are obtained for a constant specimen voltage, with limited or no atom field evaporation. When the specimen voltage is raised continuously, a nearly constant field evaporation rate can be achieved. By recording the FIM micrographs during the field evaporation process, slices of the evaporated volume are obtained, and a tomographic reconstruction of the material can be achieved by means of the three-dimensional visualization software Amira ${ }^{\circledR}$ (Vurpillot et al., 2007).

All atom probe tomography measurements were performed at $80 \mathrm{~K}$ on a CAMECA energy-compensated tomographic atom probe (ECOTAP) equipped with an ADLD detector (Da Costa et al., 2005). The pulse repetition rate was $1.7 \mathrm{kHz}$, and the pulse amplitude was set at $20 \%$ of the standing voltage. Three-dimensional reconstructions were obtained using 3Dsoft software, developed at the University of Rouen. The analysed volumes obtained have a cross-section of approximately $12 \times 12 \mathrm{~nm}^{2}$ and a depth of up to several hundred nanometres, depending on the robustness of the specimen.
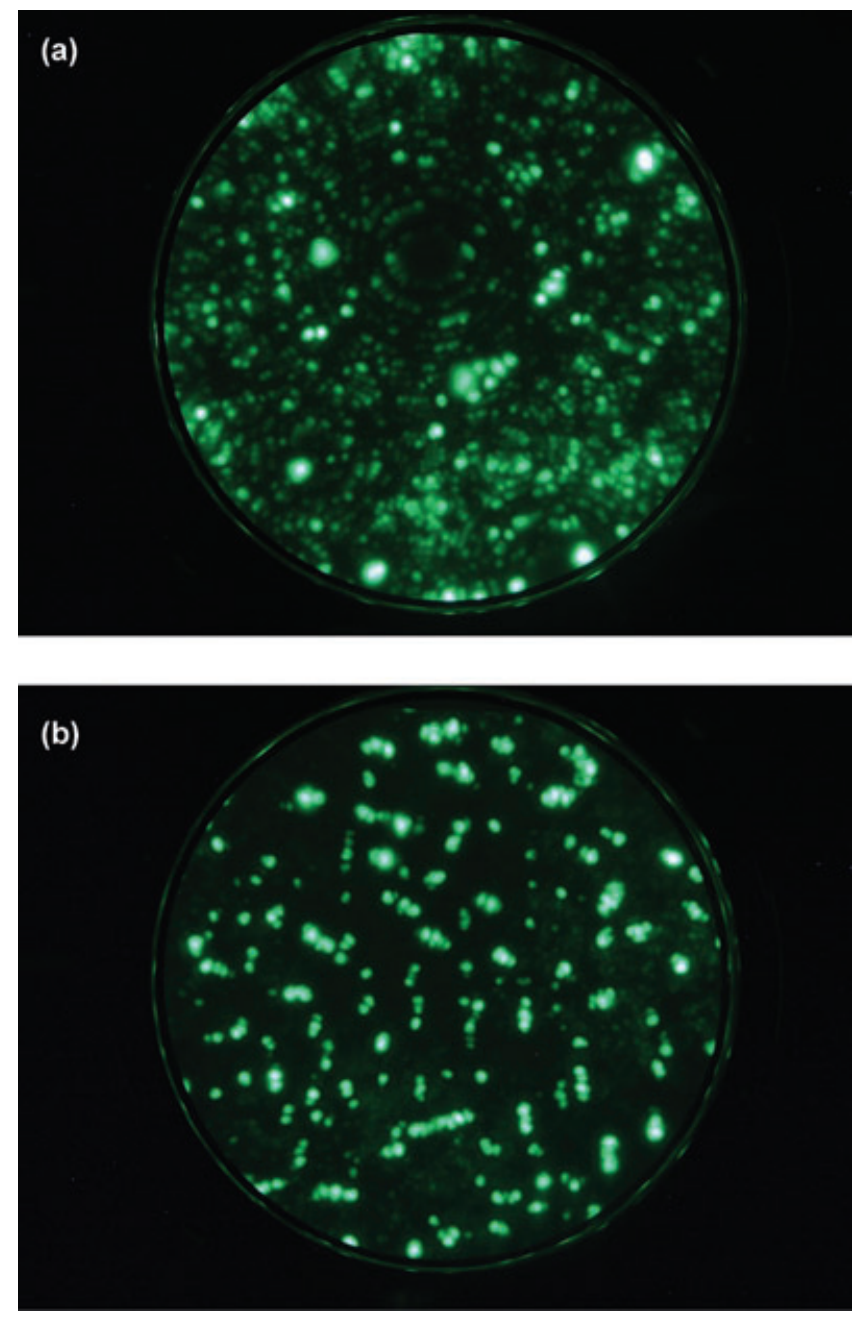

Fig. 1. Field ion micrographs obtained at $80 \mathrm{~K}$ with a Ne pressure of $5.10^{-5}$ torr. For both specimens, the applied voltage was $5.5 \mathrm{kV}$, leading to a field of view of approx. $150 \mathrm{~nm}$. (a) Al free steel; (b) steel 1014 .

\section{Results}

\section{Al free alloy}

The Al free alloy has been investigated by conventional and 3DFIMs. A typical field ion micrograph is shown Figure 1(a). As expected from alloy carbides (i.e. different from iron carbides) (Miller \& Smith, 1989; Thomson, 2000), secondary hardening carbides appear as brightly imaging regions. This is due to their higher cohesive energy, as compared to the martensitic matrix, which makes them more difficult to field evaporate. As a consequence, carbides protrude at the specimen surface, leading to local preferential field ionisation, and thus a bright contrast. Considering the lateral extent of the field ion micrograph presented in Figure 1, the average distance between carbides at the specimen surface is estimated to be about $50 \mathrm{~nm}$. This value was confirmed by the analysis of several other micrographs. It should be kept in mind that this 
value is derived from the examination of the two-dimensional specimen surface. In order to get a more realistic view of the real microstructure, and distance between particles in three dimensions, 3DFIM was conducted on this alloy.

Figure 2 shows the three-dimensional reconstruction obtained after 3DFIM investigation. This reconstruction was processed in order to highlight the distribution of carbides. The brightly imaging regions, corresponding to the secondary carbides, were artificially coloured in red, the blue region corresponding to the darkly imaging matrix. As can be seen on this reconstruction, carbides are not distributed homogeneously in the matrix, but are clearly distributed along specific lines, highlighted by the selected orientation of the reconstruction. This kind of distribution is characteristic of heterogeneous precipitation along dislocations inherited from the quench. In such martensitic steels, dislocation density is very high, and the mean distance between dislocation lines is reduced down to a few tens of nanometres, corresponding to the distance between the observed alignments of carbides. Consequently, the carbide distribution revealed in this reconstruction is most likely to be the illustration of the heterogeneous nature of the precipitation of carbides on dislocations in this $\mathrm{Al}$ free steel.

The heterogeneous distribution of secondary carbide precipitation has been reported in the literature for ferritic steels, mostly on the basis of transmission electron microscopy investigation. The alignment of precipitates along dislocation lines have been showed both from thin foil (Perrard et al., 2006) and extraction replica (Courtois et al., 2006) in the particular case of ternary experimental ferritic FeNbC steels. However, because of the highly dislocated and ferromagnetic matrix, similar transmission electron microscopy observations at the nanometre scale are very difficult to perform in martensitic steels, and carbides smaller than $5 \mathrm{~nm}$ in diameter are hardly directly discernible form the matrix (Erlach et al., 2006). In addition, the dislocation density in martensitic steels is several orders of magnitude larger than in ferritic steels, making the heterogeneous nature of the precipitation more difficult to evidence from transmission electron microscopy, but easier with 3DFIM experiments.

\section{Steel 1014}

The steel 1014 has also been investigated by FIM. A typical field ion micrograph is shown Figure 1(b). As in the previous case, secondary hardening carbides appear as brightly imaging regions. Two main conclusions can be drawn from this micrograph. The distribution of carbides is dramatically different from the one observed in the $\mathrm{Al}$ free steel. As both micrographs were obtained with the same magnification, the carbides clearly appear much smaller. Above all, carbide distribution at the specimen surface appears far more homogeneous. Indeed, the mean distance between particles at the specimen surface is about $10 \mathrm{~nm}$, which is significantly smaller that in the case of the Al free steel. The second major difference is the shape of the carbides, which are more elongated than in the previous micrograph. The observed morphology is typical of rodlike precipitates, intercepted by the hemispherical surface of the specimen. These carbides are very similar to the $\mathrm{Mo}_{2} \mathrm{C}$ carbides previously analysed in a Fe-Mo-C alloy by Davies \& Ralph (1972).

About 100 carbides can be detected in this micrograph, which is at least 10 times more that in the micrograph presented Figure1(a). Of course, due to the heterogeneous distribution of carbides in the $\mathrm{Al}$ free steel, the micrograph presented in Figure 1(a) may not be representative of the general microstructure. However, as previously explained, an average of two-three carbides could be observed simultaneously. It can therefore be concluded without any ambiguity that the number density of carbides is one to two orders of magnitude larger in the case of steel 1014. A mean interparticle distance of $10 \mathrm{~nm}$, and the number density of

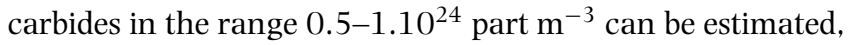
assuming an homogeneous spatial distribution.

No NiAl particle could be evidenced by FIM investigation of steel 1014, even if the precipitation has been detected by other techniques (Erlach et al., 2007). The reason for that lies in the fact that these particles have a lower cohesive energy than both carbides and matrix, which will make them appear in a darker contrast than the two other phases (Miller \& Smith, 1989; Thomson, 2000). They are therefore more difficult to detect by FIM than the brightly imaging carbides. In addition, the presence of the protruding carbides will limit imaging gas supply to the NiAl particles, making their observation even more difficult. In order to investigate the NiAl precipitation, atom probe tomography investigations were conducted on steel 1014 steel.

A typical three-dimensional atom probe tomography reconstruction showing the distribution of $\mathrm{Al}$ atoms in steel 1014 is presented Figure 3. Al rich zones are representative of the $\mathrm{NiAl}$ particles, which are shown to be present with a very high number density. Based on several analyses representing an analysed volume of $50.10^{3} \mathrm{~nm}^{3}$, the mean radius of NiAl particles is $0.9 \pm 0.1 \mathrm{~nm}$, the precipitate volume fraction is about $5 \%$, and their number density reaches $0.9 \pm 0.1$ $10^{24}$ part $\mathrm{m}^{-3}$. Of course, in the case of the $\mathrm{Al}$ free alloy, no such particles are observed.

Representative concentration profiles obtained with $3 \mathrm{~nm}$ lateral resolution and $0.1 \mathrm{~nm}$ depth resolution were extracted from analysed volumes for both alloys. Few carbides, revealed by the correlated carbon and chromium concentration fluctuations, were intercepted in the $\mathrm{Al}$ free steel, as shown in Figure 4(a). It should be noted that molybdenum follows the same trend, but was not shown for the sake of clarity. The observed distance between carbides is in the range of several tens of nanometres, in good agreement with the values derived from the field ion micrograph presented Figure 1(a). 


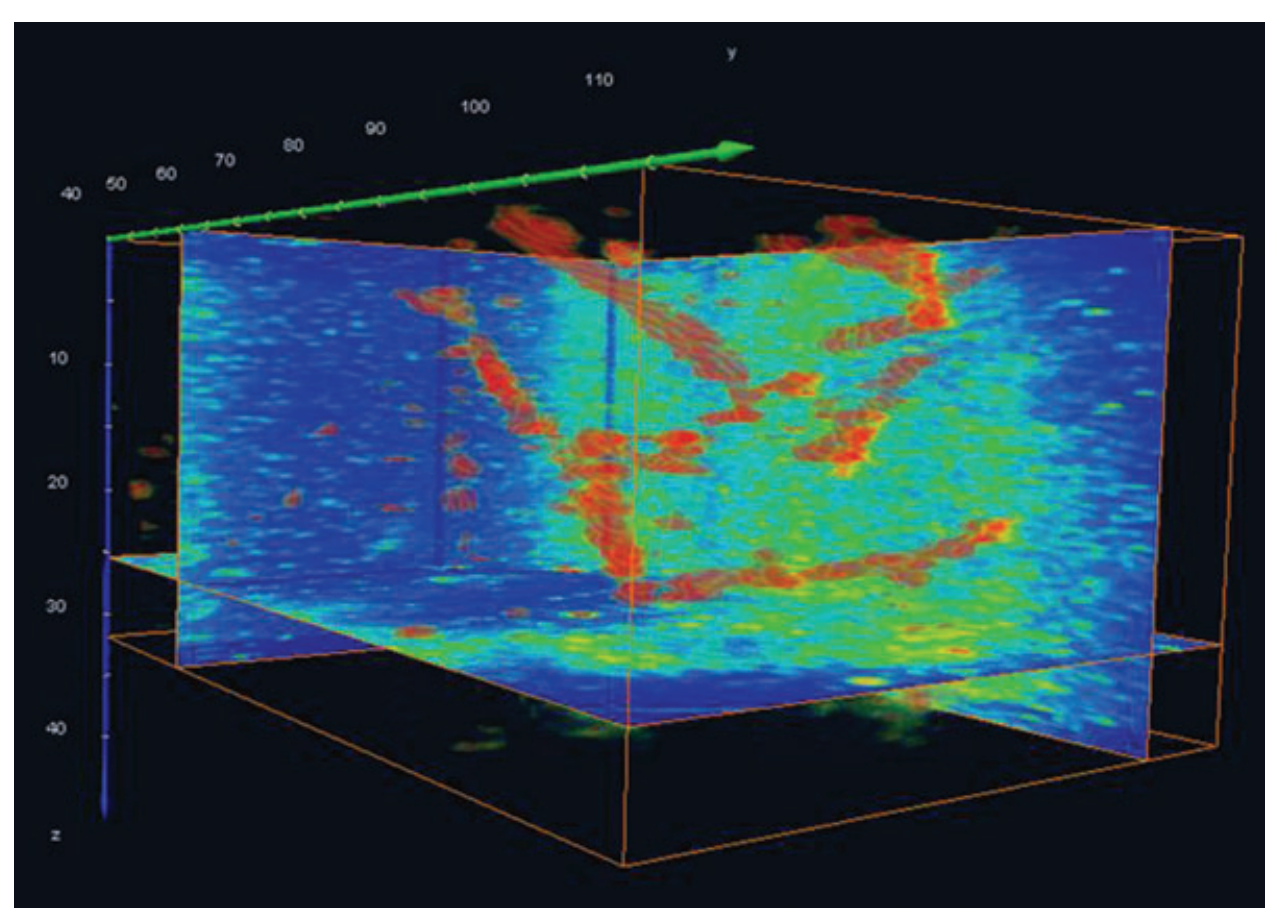

Fig. 2. 3DFIM reconstruction obtained on the $\mathrm{Al}$ free steel. Field ion micrographs were recorded during field evaporation in a mixture of $4.10^{-5}$ torr $\mathrm{Ne}+1.10^{-5}$ torr $\mathrm{H}$ at $80 \mathrm{~K}$.The volume represented is $70 \times 70 \times 30 \mathrm{~nm}^{3}$ (scales on the reconstruction are in $\mathrm{nm}$ )

Figure 4(b) shows a shorter concentration profile, derived from an analysis of steel 1014. 3 NiAl-type particles can be observed in this profile extending over $25 \mathrm{~nm}$, whereas the previous one extended over $100 \mathrm{~nm}$. The estimated distance between carbides, as derived from this one-dimensional profile, is about $10 \mathrm{~nm}$, which is in very good agreement with FIM results. The most interesting aspect deals with the evident correlation between the carbides and two of the intercepted NiAl particles, as revealed by the local variations of $\mathrm{Al}$ concentration fluctuations. Careful examination of many concentration profiles confirms that carbides are systematically associated with NiAl-type particles, and that the proportion of NiAl-type particles associated carbides with is in the order of $50 \%$. As a consequence, the number density of carbides can be estimated to be $0.510^{24}$ part $\mathrm{m}^{-3}$.

At last, it should be noted that for both types of precipitates, the stoechiometric composition (respectively, $50 \mathrm{Al}-50 \mathrm{Ni}$ and 33C-66(Mo,Cr) ) is not reached, and that the observed particles should be regarded as a transient state to the equilibrium phase. This is consistent with previous studies on a similar martensitic steel for the same ageing conditions (Erlach et al., 2007).

\section{Discussion and conclusions}

From the presented FIM and atom probe tomography experimental investigations, the mechanism of $\mathrm{M}_{2} \mathrm{C}$ carbides precipitation can be analysed in detail. In the case of the $\mathrm{Al}$ free steel, precipitation of carbides is clearly limited to lattice defects, in particular to dislocation lines, as shown in Figure 2. This is the classical mechanism of heterogeneous precipitation in steels. In the case of the commercial steel 1014 , the situation is completely different as the very high number density of carbides cannot be solely attributed to precipitation on lattice defects. In parallel, the concomitant precipitation of NiAl-type particle is clearly homogeneous in the martensitic matrix. Indeed, the mean distance between NiAl-type particles (less than $10 \mathrm{~nm}$ ) is significantly lower than the distance between dislocation lines, as derived from the distance between heterogeneously precipitated carbides.

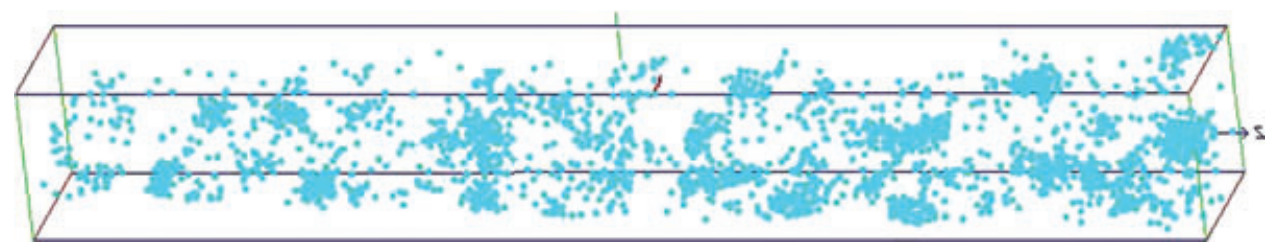

Fig. 3. Atom probe tomography reconstruction showing the distribution of $\mathrm{Al}$ atoms in steel 1014 . The represented volume is $10 \times 10 \times 70 \mathrm{~nm}{ }^{3}$. 

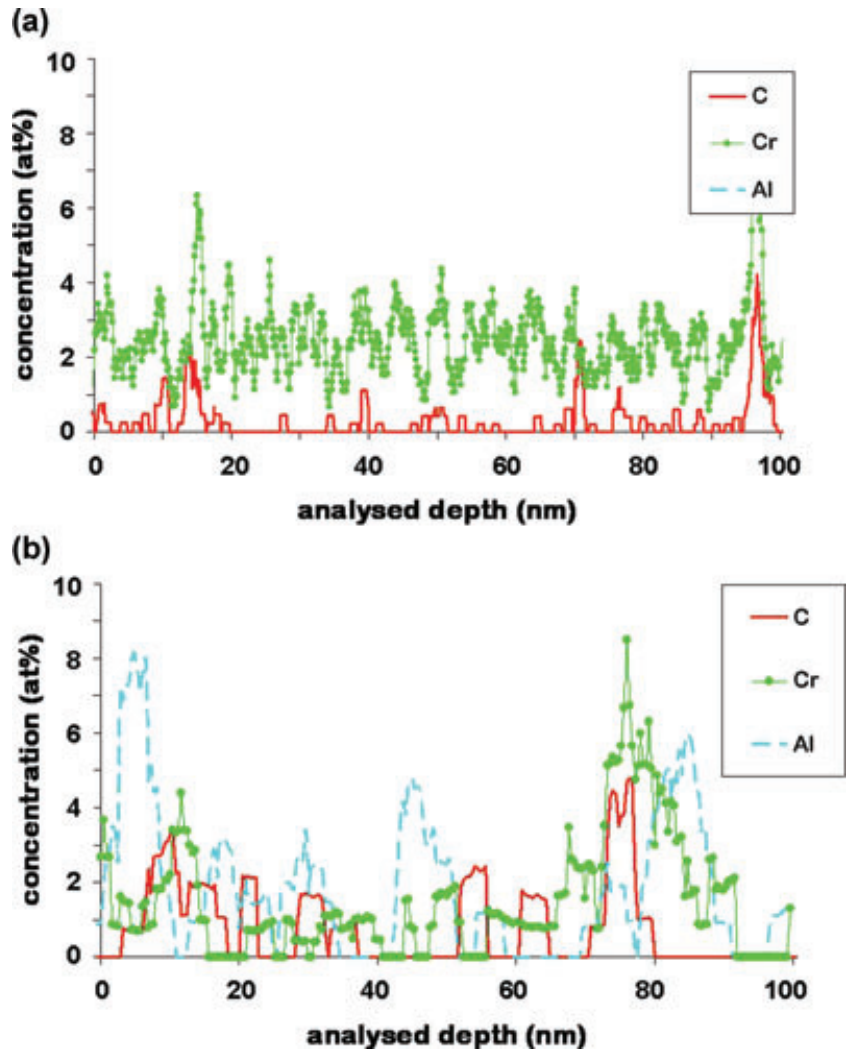

Fig. 4. Concentration profiles derived form cylinders cropped from the analysed volumes. The diameter of the cropped cylinders was $5 \mathrm{~nm}$, and concentration values are calculated over 0.1-nm-thick slices, with a smoothing window of 3 . Considering the number of atoms used to calculate each concentration value (about 400 atoms), standard deviation on presented values is less than $0.5 \mathrm{at} \%$. (a) Al free steel; (b) steel 1014 .

Even if heterogeneous precipitation of NiAl-type particles on dislocation cannot be ruled out, the vast majority of particles appear to have homogeneously precipitated in the matrix. This result is consistent with previous investigation of precipitation of NiAl in ferritic steels (Taillard et al., 1982; Blavette et al., 1982). As $\mathrm{M}_{2} \mathrm{C}$ nuclei are systematically associated with $\mathrm{NiAl}$ particles, and because the number density of carbides is smaller than the one of intermetallics, it can be concluded that the nucleation of carbides is assisted by the presence of intermetallic particles. Because of the very high number density of NiAl particles, much more nucleation sites are available in the commercial steel 1014, as compared to the $\mathrm{Al}$ free steel. As a consequence, the distribution of $\mathrm{M}_{2} \mathrm{C}$ carbides appears far more homogeneously distributed in the steel 1014.

In both steels, the carbide precipitation can be considered as heterogeneous, as the nucleation is induced by the presence of preferential sites, and consequently the formation of carbide nuclei is not the result of homogeneous composition fluctuations within the martensitic matrix, large enough to cause the second phase particles to form. Through the addition of $\mathrm{Al}$, the carbide preferential nucleation sites are changed from lattice defects (dislocation lines or lath boundaries) in the Al free steel to NiAl-type particles in the steel 1014. As these latter nucleate homogeneously throughout the martensitic matrix, the distribution of carbides is made more homogeneous in volume, even if the nucleation mechanism is still heterogeneous. The presence of NiAl-type particles results in a homogeneization of the carbide distribution.

Atomic scale evidence of the synergetic influence of a developing phase during phase transformation has already been reported in the literature. In the case of duplex stainless steels, the FeCr spinodal decomposition taking place in the ferrite was shown to induce crossed fluxes of $\mathrm{Si}$ and $\mathrm{Ni}$, resulting in the precipitation of the intermetallic $G$ phase particles localised at the alpha-alpha prime interfaces (Danoix et al., 1992). The kinetic of $G$ phase precipitation was shown to be driven by the spinodal decomposition, with a time exponent of 0.18 (Danoix et al., 1994). The governing mechanism was shown to be the evolution of solubilities of $\mathrm{Ni}$ and $\mathrm{Si}$ in the emerging alpha and alpha prime phase. The influence of interfacial energy was not considered, and this precipitation scheme was not identified as heterogeneous nucleation. In maraging steels, many investigators highlighted the role of copper on the precipitation of intermetallic phase (Sha et al., 1993; Stiller et al., 1998). It was shown that, because of a larger driving force, $\mathrm{Cu}$ particles first precipitate, and then act as sites for heterogeneous nucleation of the intermetallic phase. In both previous cases, the intermetallic phase precipitation mechanism was affected by the presence of a second phase. More recently, similar mechanism has also been reported to affect carbide precipitation in steels. In a copper bearing high strength low carbon steel, Mulholland \& Seidman evidenced the heterogeneous nucleation of secondary $\mathrm{M}_{2} \mathrm{C}$ carbides on Cu-rich precipitates (Mulholland \& Seidman, 2009). As no study of a copper-free version of the alloys has been presented, it is not possible to estimate the influence of the copper precipitates on the nucleation of the carbides as in the case of this study. Nevertheless, as no heterogeneous precipitation on dislocation lines was evidenced, and as the number density of carbide is about a fourth of the one of copper particles, it can be assumed that $\mathrm{Cu}$ particles served as sites for the heterogeneous precipitation of carbides. Latest isothermal ageing treatment confirms this hypothesis (Mulholland \& Seidman, 2011). It can therefore be concluded that the distribution of carbides is strongly dependent on the precipitation of copper (known to be homogeneous, Othen et al. (1991), and that the same proposed assisted mechanism for carbide precipitation was also operative in this other system.

As a conclusion, it has been shown that the presence of an intermetallic second phase affects the nucleation mechanism and the spatial distribution of the secondary hardening carbides in a double precipitation medium carbon martensitic steel. The nucleation is turned from heterogeneous on dislocations to heterogeneous on the NiAl particles, resulting in a homogeneous spatial distribution of the carbides in 
the matrix. The consequences of this modification on the mechanical properties of the material are out of the scope of this paper, but it is most likely that the resulting homogeneous distribution of hardening carbides will affect the mechanical response of the material. This aspect will be addressed in a further paper.

\section{Acknowledgements}

This research was conducted under ANR funded ANR-05RMNP-008-05 research program. J.A. thanks Aubert and Duval for financial support.

\section{References}

Blavette, D., Martin, C. \& Gallot, J. (1982) Analyse à la sonde atomique de précipites dans un alliage $\mathrm{Fe}^{\mathrm{Cr}_{20}} \mathrm{Ni}_{2} \mathrm{Al}_{2}$. Scripta Metallurgica. 16, 59-64.

Courtois, E., Epicier, T. \& Scott, C. (2006) EELS study of niobium carbonitride. Nano-Precipit. Ferrite Micron. 37, 492-502.

Da Costa, G., Vurpillot, F., Bostel, A., Bouet, M. \& Deconihout, B. (2005) Design of a delay-line position-sensitive detector with improved performance. Rev. Scientif. Instr. 76, doi:10.1063/1.1829975.

Danoix, F., Auger, P. \& Blavette, D. (1992) An atom-probe investigation of some correlated phase transformations in $\mathrm{Cr}$, Ni, Mo containing supersaturated ferrites. Surf. Sci. 266, 364-369.

Danoix, F., Auger, P., Chambreland, S. \& Blavette, D. (1994) A 3D study of G-phase precipitation in spinodally decomposed $\alpha$-ferrite by tomographic atom-probe analysis. Microscopy Microanal. Microstruct. 5, 121-132.

Davies, D.M. \& Ralph, B. (1972) Field ion microscopic study of quenched and tempered Fe-Mo-C. J. Iron Steel Inst. 210, 262-266.

Erlach, S., Leitner, H., Bischof, M., Clemens, H., Danoix, F., Lemarchand, D. \& Siller, I. (2006) Comparison of NiAl precipitation in a medium carbon secondary hardening steel and C-free PH13-8 maraging steel. Mater. Sci. Eng. A 429, 96-106.

Erlach, S., Danoix, F., Leitner, H., Auger, P., Siller, I. \& Clemens, H. (2007) Precipitation reactions during the early stages of aging in a $\mathrm{Ni}$ and
Al alloyed martensitic medium carbon steel. Surf. Interface Anal. 39, 213-220.

Garrison Jr. W. M. \& Strychor, R. (1988) A preliminary study of the influence of separate and combined aluminum and nickel additions on the properties of a secondary hardening steel. Metallurg. Mater Trans. A. 19A, 3103-3107.

Hamano, R. (1993) The effect of the precipitation of coherent and incoherent precipitates on the ductility and toughness of high-strength steel. Metallurg. Mater. Trans. A 24, 127-139.

Miller, M.K. \& Smith, G.D.W. (1989) Atom Probe Microanalysis: Principles and Applications to Materials Problems. Materials Research Society, Pittsburgh, PA.

Mulholland, M.D. \& Seidman, D.N. (2009) Multiple dispersed phases in a high-strength low-carbon steel: an atom-probe tomographic and synchrotron X-ray diffraction study. Scripta Materialia 60, 992-995.

Mulholland, M.D. \& Seidman, D.N. (2011) Nanoscale co-precipitation and mechanical properties of a high-strength low-carbon steel. Acta Materialia. 59, 1881-1897.

Othen, P.J., Jenkins, M.L., Smith, G.D.W. \& Phythian, W.J. (1991) Transmission electron microscope investigations of the structure of copper precipitates in thermally-aged $\mathrm{Fe}-\mathrm{Cu}$ and $\mathrm{Fe}-\mathrm{Cu}-\mathrm{Ni}$. Phil. Mag. Lett. 64, 383-391.

Perrard, F., Donnadieu, P., Deschamps, A. \& Barges, P. (2006) TEM study of $\mathrm{NbC}$ heterogeneous precipitation in ferrite. Phil. Mag. $864271-$ 4284 .

Sha W., Cerezo A., Smith G.D.W. (1993) Phase chemistry and precipitation reactions in maraging steels: part I. Introduction and study of Co-containing C-300 steel. Metallurg. Mater. Trans. A. 24A, 1221-1232.

Stiller, K., Hattestrand, M. \& Danoix, F. (1998) Precipitation in 9Ni-12Cr2Cu maraging steels. Acta Materialia 46, 6063-6073.

Taillard, R., Pineau, A. \& Thomas, B.J. (1982) The precipitation of the intermetallic compound $\mathrm{NiAl}$ in $\mathrm{Fe}-19$ wt.\%Cr alloys. Mater. Sci. Eng. 54, 209-219.

Thomson, R.C. (2000) Characterization of carbides in steels using atom probe field-ion microscopy. Mater. Charact. 44, 219-233.

Vurpillot, F., Gilbert, M. \& Deconihout, B. (2007) Towards the threedimensional field ion microscope. Surf. Interf. Anal. 39 273-277. 